\title{
Reutilização de Informação Clínica para Investigação: 0 Modelo da Pegada Científica do Centro Hospitalar de São João
}

\section{Reutilization of Clinical Data for Research: The Footprint Scientific Model of the Hospital Center of São João}

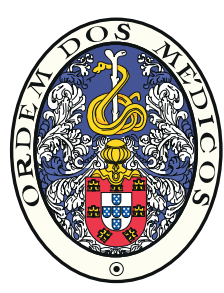

Rui GUIMARÃES $\square^{1,2,3}$, Ricardo Jorge DINIS-OLIVEIRA*1,4,5, Altamiro PEREIRA*2, Pedro RODRIGUES ${ }^{* 2}$, Agostinho SANTOS*1

Acta Med Port 2017 Mar;30(3):159-162 - https://doi.org/10.20344/amp.8592

Palavras-chave: Investigação Biomédica; Projectos de Investigação; Registos Clínicos

Keywords: Biomedical Research; Health Records; Research Design

\section{INTRODUÇÃO}

Os registos clínicos eletrónicos (EHR) ou de outro tipo de suporte têm uma informação de natureza sensível que encontra particular fundamento no impacto que a violação destes pode vir a ter, até, na esfera jurídica de nascituros ou de concepturos. A privacidade, bem com proteção jurídica constitucional nos ordenamentos jurídicos dos Estados Membros da União Europeia e em documentos fundamentais do próprio Parlamento e do Conselho Europeus, tem, no domínio específico dos registos clínicos, a sua expressão diária no segredo médico, no dever de sigilo do médico e demais profissionais de saúde, enquanto dever inerente e resultante do direito à confidencialidade, por parte dos doentes (Diretivas 2003/98/CE, de 17 de novembro, e 2013/37/UE, de 26 de junho). Ao hospital cabe a responsabilidade legal de garantir a guarda desse património informacional que são os registos clínicos, a informação de saúde, produzida na sequência da sua atividade de prestação de cuidados.

A investigação científica, no caso vertente também clínica, vive, de forma significativa, do acesso e (re)utilização de registos clínicos produzidos e resultantes da atividade de prestação de cuidados. Em nome da sociedade do conhecimento, os investigadores europeus, têm o direito de aceder, neste caso a registos clínicos, na posse e à guarda dos hospitais, e utilizar, em rigor (re)utilizar os mesmos para fins de investigação e desenvolvimento (I\&D), garantida que esteja a obrigatoriedade de anonimização dos mesmos. Os beneficiários vão desde a comunidade científica, aos médicos, e de repercussão óbvia nos doentes e na própria liderança das instituições. Alocar recursos à investigação é assim, não uma despesa, mas um investimento com alto retorno e não apenas financeiro.
Por outro lado, os doentes, legítimos proprietários, as pessoas a quem os registos dizem respeito, têm um direito de privacidade e, no nosso caso, também um direito de propriedade. Na verdade, como subproduto da prestação de cuidados aos doentes, exponenciais quantidades de registos clínicos são produzidos e armazenados em bases de dados. ${ }^{1}$ Song e colegas ${ }^{2}$ chamam a atenção para o elevado custo da investigação clínica tradicional, suportada em ensaios clínicos, onde os resultados são lentos, difíceis de inscrição e muitas vezes pobres na generalização, sendo esta uma das razões para a mais-valia que representa a reutilização dos registos clínicos que resultam da prestação de cuidados.

No entanto, os registos clínicos que resultam da prestação de cuidados têm várias limitações, na sua reutilização para a investigação, comparativamente com os registos que resultam de ensaios clínicos. Desde logo, porque são elaborados para a prestação de cuidados clínicos, e não para fins de investigação científica. Por outro lado, os registos feitos no âmbito da prestação de cuidados de saúde, não são, em regra, muito padronizados. ${ }^{3}$ Muitos sistemas que suportam os registos clínicos na prestação de cuidados favorecem o texto livre, em detrimento da inscrição de dados estruturados o que implica défices de qualidade significativos. ${ }^{3}$ Além disso, os registos clínicos nem sempre estão acessíveis e existem barreiras culturais e organizacionais nomeadamente motivadas por não estarem assegurados os direitos dos doentes, privacidade e confidencialidade. ${ }^{4}$ Matsumura e colegas ${ }^{5}$ desenvolveram um módulo de plug-in de interface, utilizando o Open EHR para gerar dados estruturados para serem reutilizados na investigação.

Apesar da existência, em todo o espaço europeu, de

\footnotetext{
* Co-primeiros autores.

1. Department of Public Health and Forensic Sciences, and Medical Education. Faculdade de Medicina. Universidade do Porto. Porto. Portugal.

2. MEDCIDS - Department of Community Medicine, Health Information and Decision. Faculdade de Medicina. Universidade do Porto. Porto. Portugal.

3. Hospital Centre São João. Porto. Portugal.

4. Department of Sciences. IINFACTS - Institute of Research and Advanced Training in Health Sciences and Technologies. Instituto Universitário de Ciências da Saúde - IUCS.

Cooperativa de Ensino Superior Politécnico e Universitário. Gandra. Portugal.

5. UCIBIO-REQUIMTE, Laboratory of Toxicology. Department of Biological Sciences. Faculdade de Farmácia. Universidade do Porto. Porto. Portugal.

$\square$ Autor correspondente: Rui Guimarães: ruiguimaraes@med.up.pt

Recebido: 22 de dezembro de 2016 - Aceite: 24 de fevereiro de 2017 | Copyright @ Ordem dos Médicos 2017
} 
um quadro legal, transposto pelos Estados Membros para os seus ordenamentos jurídicos, onde se consagra o direito que os investigadores têm de reutilizar registos clínicos para fins I\&D, a verdade, é que tanto quanto é do nosso conhecimento, não é prática, nem conhecemos qualquer menção expressa e inequívoca aos termos e enquadramento jurídico que consentiu o acesso aos registos clínicos utilizados nas investigações por parte dos investigadores. Desconhecemos pois os termos em que o acesso é consentido e viabilizado, em rigor, reutilizado, na investigação. Desconhecemos mesmo se tais acessos não ocorrem de forma ilegítima, sustentados em práticas consuetudinárias, relativamente às quais a sua conformidade com o direito não é sequer questionada, com prejuízo dos titulares da informação, e à revelia dos diferentes bens jurídicos que o direito tutela. Esta completa e total omissão do enquadramento jurídico que tem vindo a sustentar a reutilização de registos clínicos para fins de investigação, não garante a proteção dos direitos das pessoas a quem os registos clínicos dizem respeito.

A tudo isto acresce, a realidade da fraude nos trabalhos científicos, com a expressão e dimensão concluída em vários estudos e denunciada por investigadores que põe a descoberto as consequências da pressão académica para publicar. ${ }^{6} \mathrm{~A}$ fraude na investigação científica na área biomédica, tem expressão na manipulação da informação e na difícil, quando não mesmo impossível, reprodutibilidade da investigação, não apenas por desconhecimento rigoroso e preciso das fontes, mas também, pela falta de citação precisa das mesmas, nos termos do $n^{\circ} 3$, do artigo $21^{\circ}$, da Lei n. ${ }^{\circ} 26 / 2016$, de 22 de agosto.

É neste quadro e com estas motivações, que os autores, no decurso das suas atividades científicas e académicas universitárias, e no desempenho de funções legais de Responsável pelo Acesso à Informação (RAI) do Centro Hospitalar de São João (CHSJ), se propõem conceber, construir e viabilizar uma Certidão de Reutilização, a DAta Reuse Certificate for Research (DARE). Com esta certidão, pretendemos: i) atestar de forma expressa e inequívoca, o enquadramento jurídico que consentiu o acesso do investigador ao património informacional, neste caso aos registos clínicos, na posse e à guarda legal de uma unidade de saúde, contribuindo de forma decisiva e eficazmente, quer para a transparência da investigação científica, quer para a possibilidade de a tornar de facto reprodutível e auditável; e ii) garantir a idoneidade, honorabilidade e o rigor científico da investigação, porque atesta as fontes utilizadas, constituindo uma segurança jurídica quer para os investigadores, quer para as unidades de investigação que a tutelam, quer ainda, e de um modo geral, para todos os beneficiadores do conhecimento científico de natureza clínica.

\section{Fases da criação do DARE}

O pedido de acesso a registos clínicos para I\&D ou fins educativos, encontra o seu suporte jurídico, na Diretiva 2013/37/UE do Parlamento Europeu e do Conselho de 26 de junho de 2013 que altera a Diretiva 2003/98/CE relativa à reutilização de informações do setor público, e na Lei n. ${ }^{\circ}$ 26/2016, de 22 de agosto. Nos termos destes instrumentos jurídicos, a reutilização de documentos tem dois domínios distintos: fins educativos ou de I\&D. No presente trabalho, vamos ocupar-nos exclusivamente da reutilização no domínio específico da I\&D.

No sítio web do Centro Hospitalar de São João, EPE, no espaço de 'Inovação' foi concebido um campo específico e exclusivamente dirigido aos pedidos de reutilização de registos clínicos para fins de I\&D, coordenado e dirigido obrigatoriamente pelo RAI, já que a autorização para reutilização é matéria legal da sua competência exclusiva, independentemente de outros pareceres a que haja lugar. Com intuitos pedagógicos, acrescenta que reutilização significa "a utilização por pessoas singulares ou coletivas de documentos na posse de organismos do sector público, para fins comerciais ou não comerciais diferentes do fim inicial de serviço público para o qual os documentos foram produzidos". O modelo do Pedido de Reutilização de Registos Clínicos para I\&D pode ser consultado no sítio web do Centro Hospitalar de São João. ${ }^{7}$

Após a submissão do pedido de acesso a registos clínicos para fins de investigação, o RAl afere a legitimidade de quem pede e a legitimidade do pedido, nos termos da lei, da doutrina e da jurisprudência. No caso de indeferir o pedido, fundamenta a sua decisão e informa o requerente das razões de recusa, bem como das garantias de recurso administrativo e contencioso de que o requerente dispõe, nomeadamente a apresentação de queixa junto da Comissão de Acesso aos Documentos Administrativos (CADA), e a intimação judicial da entidade requerida. Na circunstância de autorizar, que é a mais comum, informa-se o investigador indicando algumas das garantias inerentes à possibilidade dos registos clínicos reutilizados na investigação poderem ser auditados, e como tal, dar efetiva reprodutibilidade e transparência à sua investigação. Estas mais-valias interessam naturalmente i) ao próprio investigador; ii) aos seus orientadores se existirem; iii) aos proprietários da informação, os doentes a quem os registos clínicos dizem respeito; iv) às unidades de saúde enquanto instituições que têm a responsabilidade legal pela guarda dos registos clínicos; v) à instituição que tutela a investigação; vi) às editoras de revistas científicas; e ainda vii) a todas as pessoas, singulares ou coletivas, de direito privado ou de direito público, para quem a investigação tenha qualquer tipo de impacto. Terminada a consulta dos processos a que o investigador teve acesso, o RAI do Centro Hospitalar de São João, emite-Ihe uma DARE (Fig. 1) com um número único, definitivo, e irrepetível. Se o investigador solicitar a DARE, assume os compromissos de:

a) Entregar ao RAI, uma listagem de todos os processos que consultou no âmbito da autorização que lhe foi concedida, no modelo predefinido. ${ }^{7}$ Esta listagem irá ser assinada pelo investigador e pelo RAI com assinaturas digitais qualificadas e fará parte integrante do DARE, não sendo, obviamente, de acesso público, mas apenas de acesso a quem mostrar ter um interesse pessoal, direto, 


\title{
Certidão de Reutilização de Registos Clínicos para fins de investigação DAtaREuseCertificate for Research(DARE) ${ }^{1}$
}

\author{
CertificateNumber00000000 ${ }^{2}$ \\ A presente certidão está disponível no endereço:http://portal-chsj.min-saude.pt/p/DAtaREuseCertificate ${ }^{3}$
}

Rui António da Cruz de Vasconcellos Guimarães, Administrador Hospitalar do Centro Hospitalar de São João, EPE, (CHSJ) e Responsável pelo Acesso à Informação (RAI), nomeado pelo Conselho de Administração em 3 de Abril de 2008, e em 17 de março de 2016 , nos termos do artigo 9o da Lei n.o 26/2016, de 22 de agosto, certifica, que os registos clínicos ${ }^{4}$ cujo acesso foi autorizado ao investigador, para trabalho de investigaçãoclínica

pertencem ao património informacional à guarda desta instituição Hospitalar e Universitária, e que o seu acesso e reutilização para fins de investigação, ocorreu, no quadro da Lei n.o 26/2016, de 22 de agosto, lei que regula o acesso aos documentos administrativos e a sua reutilização e transpõe para a ordem jurídica nacional as Directivas n.o 2003/98/CE e 2013/37/EU, respetivamente de 17 de Novembro de 2003 e de 26 junho 2013, ambas do Parlamento e do Conselho Europeu.

A pedido do investigador, e por ser verdade, emito a presente certidão, datando-a, assinando-a, e atribuindo-lhe um número único, sendo a mesma autenticada com assinatura digital qualificada, nos termos do Decreto-Lei n. 290-D/99, de 2 de agosto.

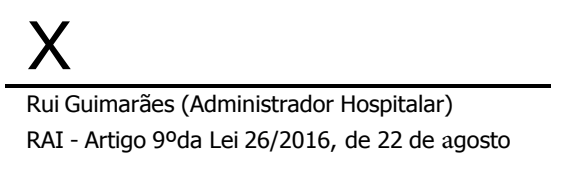

rai@chsj.min-saude.pt

\begin{abstract}
${ }^{1}$ O fenómeno da reutilização, consagrado quer na alínea g, do n.o 1, do art.o 3, da Lei n.o 26/2016, de 22 de agosto, quer em Directivas do Parlamento e do Conselho, designadamente a Directiva n.o 2003/98/CE, de 17 de novembro, e a Directiva n. 2013/37/EU, de 26 de junho de 2013, "Reutilização" significa a utilização por pessoas singulares ou colectivas de documentos na posse de organismos do sector público, para fins comerciais ou não comerciais diferentes do fim inicial de serviço público para o qual os documentos foram produzidos.

A presente DAtaREuse Certificate for Research (DARE), visa: por um lado afirmar de forma expressa e inequívoca, o enquadramento jurídico que consentiu o acesso e reutilização do investigador ao património informacional, neste caso aos registos clínicos na posse e à guarda legal do Centro Hospitalar de São João, EPE, questão fundamental, já que constitui garantia de equilíbrio entre todos os bens jurídicos em presença, designadamente o direito de reutilizar para investigar e o direito de privacidade das pessoas a quem os registos clínicos dizem respeito; por outro lado, a citação precisa e rigorosa das fontes, suportada na listagem DARE, permite, igualmente, garantir e atestar a idoneidade das fontes, os registos clínicos, quer numa perspetiva da sua origem e qualidade, quer ainda nos planos da integridade e autenticidade da informação fonte da investigação, identificando-a, e localizando-a, no suporte e no tempo de tal forma que a investigação clínica passa a ser efetivamente transparente, porque absolutamente reprodutível e auditável.

${ }^{2}$ Os dois primeiros dígitos a contar da esquerda, indicam o ano da emissão da certidão.

${ }^{3} \mathrm{~A}$ publicitação da presente certidão no endereçohttp://portal-chsi.min-saude.pt/p/DAtaREuseCertificatepermite a pesquisa pelo nome do investigador ou pelo número da certidão, a quem quiser esclarecer ou confirmar, quer o enquadramento jurídico que consentiu no acesso, quer as fontes utilizadas na investigação.

${ }^{4}$ Para garantia jurídica, quer do investigador e de quem o tutela, quer da instituição responsável pela investigação, quer dos proprietários da informação, e de quem tem a responsabilidade legal pela sua guarda, quer ainda, de quem edite a presente investigação, em anexo à presente certidão, dela fazendo parte integrante e na guarda e posse do RAI, consta uma listagem, Anexo DAtaREuseCertificate for Research(DARE), com o número de todos os processos a que o investigador teve acesso, bem como a indicação do suporte em que the foi consentido o acesso para fins de reutilização.
\end{abstract}

Figura 1 - Modelo de certidão de reutilização de registos clínicos para fins de investigação DAtaREuseCertificate for Research (DARE). 
legítimo, suficientemente relevante e proporcional, nos termos da lei;

b) De a citar, sempre que publicar e, ou, publicitar a investigação, fizer uma conferência ou exibir um poster, indicando o número da mesma e o endereço onde quem estiver interessado, pode confirmar a sua existência e autenticidade;

c) Está também a autorizar que a mesma seja publicitada no referido endereço, com a indicação expressa do seu nome, do título da investigação que levou a cabo, e da referida DARE, em vários idiomas.

Por fim, informa-se que a DARE, vai ser publicitada e ficar disponível no sítio web, podendo a pesquisa ser feita, pelo seu número, ou pelo nome do investigador.

\section{Discussão e futuras perspetivas}

Neste trabalho propomos um novo instituto jurídico com o acrónimo DARE que, suportado na lei, permita a plena auditoria e reprodutibilidade da investigação científica, contribuindo assim para a sua transparência. Trata-se de um instituto jurídico de adesão voluntária, sendo um ato de liberdade do investigador, solicitar, ou não, o DARE ao RAI, essa autorização, enquanto entidade com a competência legal para decidir do acesso e reutilização dos registos clínicos à guarda legal e institucional da unidade de saúde. A entidade pública, as unidades de saúde, que têm à sua responsabilidade a guarda legal, neste caso de registos clínicos, atestam, por esta via, qual o enquadramento jurídico que consentiu e viabilizou o acesso e reutilização, dando assim garantias, quer aos proprietários da informação sobre os motivos que legitimaram o acesso e reutilização, quer aos investigadores e centros de investigação, quer a quem vai publicar as investigações, que a lei foi cumprida e nessa medida acautelados os bens jurídicos por si tutelados.

Acreditamos que, a médio prazo, este instrumento, a
DARE, venha a ser inclusive uma exigência/pré-requisito imperativo das editoras de revistas científicas, como condição prévia para a garantia de uma maior qualidade e idoneidade da informação que suporta a investigação científica de natureza clínica. Por outro lado, as unidades de saúde, responsáveis pela guarda deste património tão sensível, reagirão construtivamente em prol da melhoria ao serem mencionadas como fontes de um património informacional que necessariamente passa a ser objeto de um escrutínio, que até à data tem pouca expressão e visibilidade pública. É também evidente que a citação da DARE, com a indicação do número respetivo, e a sua inscrição pelo investigador, no próprio processo clínico, no ato de acesso e reutilização do mesmo, elucida e garante, a fundamentação da legitimidade do acesso, daquele investigador, àquele processo, naquele suporte e àquela data, deixando uma pegada científica que testifica o seu reuso naquela investigação concreta. Neste processo, e porque é da prestação de cuidados de saúde, núcleo central da missão da Entidade Reguladora da Saúde (ERS), que resultam os registos clínicos, a intervenção desta entidade, pode e deve ser complementar na verificação da legalidade na reutilização dos mesmos. O investigador tem, também de estar ciente da necessidade de solicitar as pertinentes autorizações à Comissão Nacional de Proteção de Dados (CNPD), sempre que tal se justificar como acontece aquando da construção de bases de dados. No futuro pretendemos ainda estender este instituto jurídico a outras áreas científicas não clínicas, o que desde logo fundamenta a legitimidade do acesso à informação reutilizada.

\section{AGRADECIMENTOS}

Ricardo Dinis-Oliveira agradece à Fundação para a Ciência e a Tecnologia (FCT) pela sua Investigator Grant (IF/01147/2013).

\section{REFERÊNCIAS}

1. Danciu I, Cowan JD, Basford M, Wang X, Saip A, Osgood, et al Secondary use of clinical data: the Vanderbilt approach. J Biomed Inform. 2014;52:28-35.

2. Song M, Liu K, Abromitis R, Schleyer TL. Reusing electronic patient data for dental clinical research: a review of current status. J Dent. 2013;41:1148-63

3. Kreuzthaler M, Schulz S, Berghold A. Secondary use of electronic health records for building cohort studies through top-down information extraction. J Biomed Inform. 2015;53:188-95.

4. Dentler K, ten Teije A, de Keizer N, Cornet R. Barriers to the reuse of routinely recorded clinical data: a field report. Stud Health Technol

Inform. 2013:192:313-7.

5. Matsumura Y, Hattori A, Manabe S, Tsuda T, Takeda T, Okada K, et al. A strategy for reusing the data of electronic medical record systems for clinical research. Stud Health Technol Inform. 2016;228:297-301.

6. Dinis-Oliveira RJ. Magalhaes T. The inherent drawbacks of the pressure to publish in health sciences: good or bad science. F1000Res. 2015;4:419.

7. Centro Hospital de São João, Guimarães R. Reutilização de registos clínicos. 2016. [consultado 2017 fev 03]. Disponível em: https://portalchsj.min-saude.pt/pages/714. 